\title{
Macaca nemestrina
}

National Cancer Institute

\section{Source}

National Cancer Institute. Macaca nemestrina. NCI Thesaurus. Code C161033.

A medium sized macaque with a buff brown color and a short tail that is held semi-erect, found in Southern Thailand, Malaysia and Indonesia. 